\title{
MOSTOWE OBIEKTY SYSTEMU MATIÈRE - DOŚWIADCZENIA PROJEKTANTA
}

\begin{abstract}
Artykuł dotyczy jednoprzęsłowych mostów gruntowo-powłokowych o przeznaczeniu komunikacyjnym, z zastosowaniem prefabrykatów żelbetowych systemu Matière CM4 $40 \mathrm{~m}^{2}$. Mosty te zaprojektowane są przez autora referatu. Zbudowane są one w ciągu drogi ekspresowej nad rzeką Banoge w Irlandii. Na przykładzie tych obiektów omówiono niektóre zalety i wady systemu Matière CM4 ze szczególnym uwzględnieniem: projektowania, procesu budowy, kosztów wykonania oraz zachowania się tych mostów w trakcie użytkowania. W podsumowaniu autor dzieli się wiedzą i doświadczeniem, jakie nabył przy projektowaniu zintegrowanych mostów oraz formułuje zalecenia dotyczące ich projektowania i budowy w Polsce.
\end{abstract}

Słowa kluczowe: most zintegrowany, obiekt gruntowo-powłokowy, system Matière CM4, most jednoprzęsłowy, projektowanie i budowa.

\section{Wstęp}

Artykuł ten poświęcony jest projektowaniu i budowie zintegrowanych mostów gruntowo-powłokowych systemu Matière CM4, wykonanych z prefabrykowanych elementów żelbetowych. W pracach [1,2] opisane są inne typy mostów zintegrowanych, takich jak mosty jednoprzęsłowe oraz dwuprzęsłowe.

\section{Przykłady zintegrowanych mostów gruntowo-powłokowych}

Opisywane mosty A i B to zintegrowane obiekty gruntowo-powłokowe systemu Matière CM4, $40 \mathrm{~m}^{2}$, (rys. 1, 2). Obiekty te są o konstrukcji jednoprzęsłowej i w kształcie łuku. Wykonano je z prefabrykowanych elementów żelbetowych i zbudowano na obwodnicy miasta Gorey koło miasta Dublin w Irlandii. Most A znajduje się pod drogą ekspresową E01, dwujezdniową z pasem rozdziału. Most B znajduje się pod drogą jednojezdniową służącą jako droga dojazdowa do drogi ekspresowej E01.Obydwie konstrukcje położone są blisko siebie i przekraczają tą samą rzekę Banoge. Zaprojektowano je w firmach konsultingowych z Irlandii $[9,11]$. Autor jest projektantem czterech

\footnotetext{
${ }^{1}$ Andrzej Helowicz, Politechnika Wrocławska, Wybrzeże Wyspiańskiego 27, 50-370 Wrocław, tel. +48 71 3204852, andrzej.helowicz@ pwr.edu.pl
} 


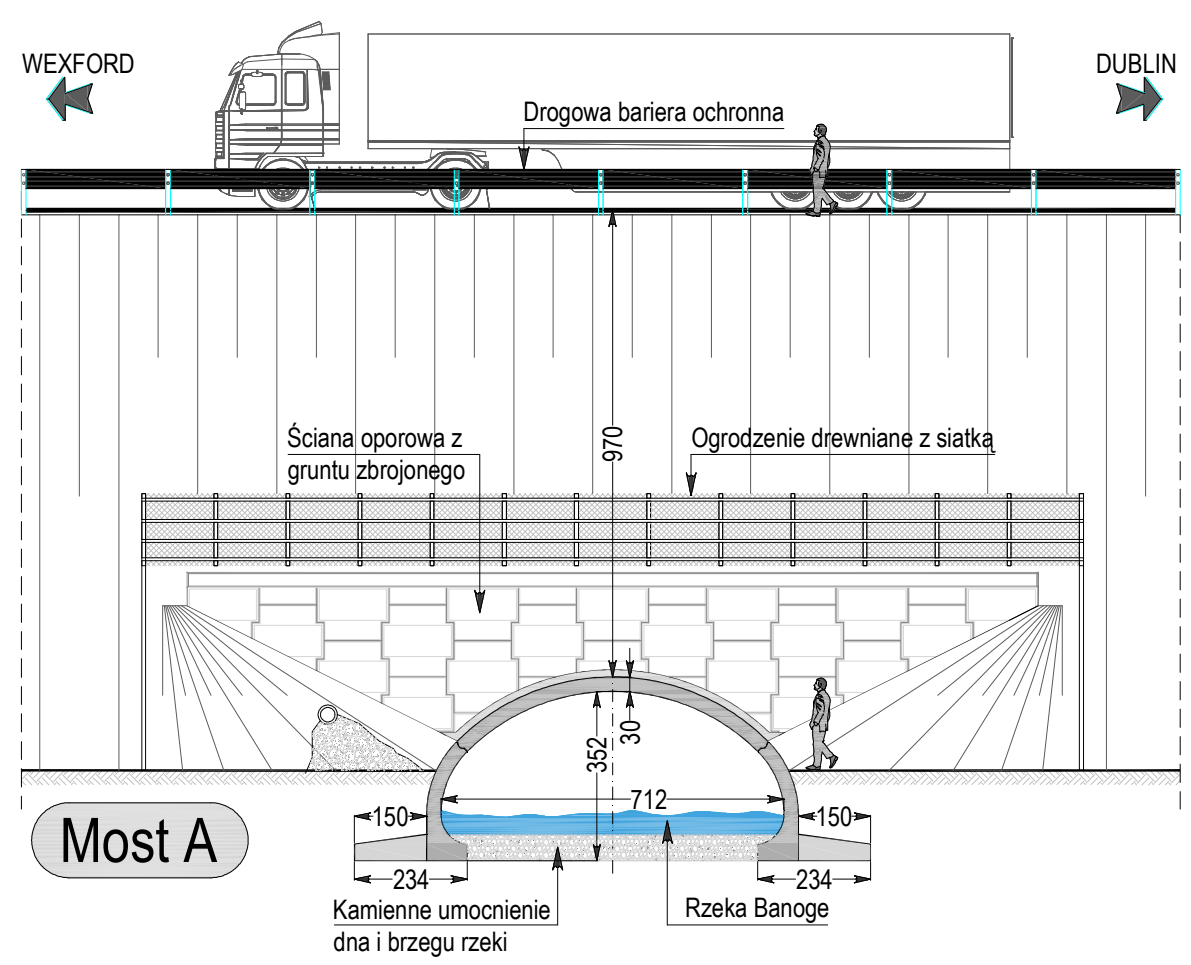

Rys. 1. Widok z boku na most A

Fig. 1. A side view of the bridge A

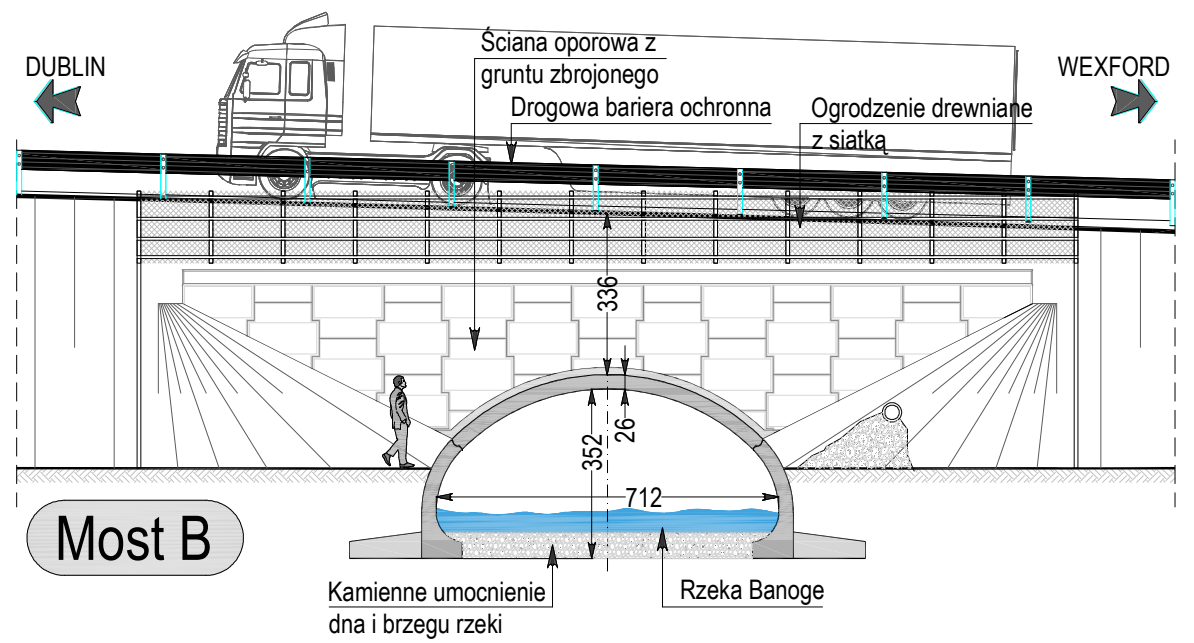

Rys. 2. Widok $\mathrm{z}$ boku na most $\mathrm{B}$

Fig. 2. A side view of the bridge $B$ 
takich mostów na odcinku nowej obwodnicy miasta Gorey. Zaprojektował on również kilku takich mostów w innych częściach Irlandii.

Ze względu na współpracę konstrukcji tych mostów z otaczającym je gruntem, posadowiono je na poduszkach kamiennych z kruszywa klasy 6N/6P, ułożonych na gruncie rodzimym. W mostach tych występują żelbetowe przeguby łączące części boczne łuku ze stropem łuku oraz żelbetowe ławy fundamentowe wykonane na budowie. Ławy fundamentowe tych obiektów znajdują się od strony wewnętrznej nasypu. W celu skrócenia długości tych mostów na początku i na końcu obu konstrukcji zastosowano ściany oporowe $\mathrm{z}$ gruntu zbrojonego. W obiektach tych nie stosuje się dylatacji w jezdni drogowej. Rzeka Banoge na czas budowy została przekierowana do sztucznie wykonanego koryta rzeki przy budowanych mostach.

Do zaprojektowania mostów wykorzystano między innymi normy:

- Obciążenia mostów zintegrowanych BA42/96 [3],

- Obciążenia mostowe BD37/01 [4],

- Wymiarowanie elementów żelbetowych BS5400-04 [6],

- Projektowanie zasypanych ziemią betonowych konstrukcji skrzynkowych i ramowych [5].

Dodatkowo przy projektowania wykorzystano irlandzkie specyfikacje techniczne do robót drogowych [12] i najnowsze zalecenia podane przez inwestora [8]. Do zaprojektowania ścian oporowych wykorzystano normę pt. „Wzmacnianie, zbrojenie gruntów i zasypek gruntowych" [7],

Ze względu na współpracę mostu zintegrowanego z gruntem, w dalszej części opisano posadowienie tych mostów oraz ważne elementy konstrukcyjne takie jak: łuk i zasypkę za ścianami bocznymi łuku.

\section{Posadowienie}

W miejscu posadowienia obydwu konstrukcji znajduje się bardzo sztywny żwir gliniasty. Na podstawie przeprowadzonych badań określono jego nośność na $300 \mathrm{kPa}$. Ze względu na wysoki nasyp przebiegający w miejscu posadowienia obydwu mostów, (tab. 1) na ich konstrukcje oddziałują duże obciążenia stałe. Obciążenia stałe w sumie ze zmiennymi powodują, że naprężenia pod stopami mostu A przekraczają prawie dwukrotnie wartości naprężeń dopuszczalnych i wynoszą $510 \mathrm{kPa}$. Jest to wartość średnia naprężenia pod stopą tego mostu. Ze względu na to, że obydwa mosty zaprojektowano jako konstrukcje zintegrowane $\mathrm{z}$ otaczającym je gruntem, zrezygnowano $\mathrm{z}$ kosztownego posadowienia pośredniego tych mostów na palach i zastosowano wymianę gruntu rodzimego na warstwę z kruszywa łamanego klasy 6N/6P o znacznie wyższej nośności od gruntu usuniętego (tab. 2). W moście A usunięto warstwę głębokości $2 \mathrm{~m}$, natomiast $\mathrm{w}$ moście $\mathrm{B} 1 \mathrm{~m}$. Zasięg wymienionego gruntu poza obrys konstrukcji pokazano na rysunku 3 . W efekcie naprężenia od działających na most obciążeń stałych i zmiennych zostały zredukowane do wartości poniżej dopuszczalnej nośności gruntu rodzimego. 
Tabela 1. Podstawowe parametry mostu A i B

Table 1. The basic information of the bridge A and $\mathrm{B}$

\begin{tabular}{|c|c|c|}
\hline Elementy & Most A & Most B \\
\hline Rozpiętość łuku & $\mathrm{L}_{\mathrm{t}}=7,42[\mathrm{~m}]$ & $\mathrm{L}_{\mathrm{t}}=7,38[\mathrm{~m}]$ \\
\hline Długość całkowita mostu & $\mathrm{B}=62,7[\mathrm{~m}]$ & $\mathrm{B}=27,6[\mathrm{~m}]$ \\
\hline Długość pojedynczego prefabrykatu & $\mathrm{B}_{\mathrm{p}}=2,49[\mathrm{~m}]$ & $\mathrm{B}_{\mathrm{p}}=2,49[\mathrm{~m}]$ \\
\hline $\begin{array}{c}\text { Konstrukcja łuku i ławy fundamentowej } \\
\text { wykonana jest z betonu klasy }\end{array}$ & $\mathrm{C} 40 / 50$ & $\mathrm{C} 40 / 50$ \\
\hline Kąt skrzyżowania obiektu z przeszkodą & $\alpha=74^{0}$ & $\alpha=80^{0}$ \\
\hline $\begin{array}{c}\text { Liczba pełnych sekcji łuku o długości } \\
2,49 \text { [m] }\end{array}$ & $23[\mathrm{szt}]$. & $9[\mathrm{szt}]$. \\
\hline Długość skrzydełek & $2,49[\mathrm{~m}]$ & $2,49[\mathrm{~m}]$ \\
\hline Wysokość konstrukcyjna łuku & $\mathrm{h}_{\mathrm{k}}=3,82[\mathrm{~m}]$ & $\mathrm{h}_{\mathrm{k}}=3,78[\mathrm{~m}]$ \\
\hline Grubość łuku & $\mathrm{h}_{\mathrm{s}}=300[\mathrm{~mm}]$ & $\mathrm{h}_{\mathrm{s}}=260[\mathrm{~mm}]$ \\
\hline $\begin{array}{c}\text { Pole przekroju poprzecznego łuku, bez } \\
\text { części ław fundamentowych wylewanych } \\
\text { na mokro }\end{array}$ & $\mathrm{A}_{\mathrm{s}}=4,16\left[\mathrm{~m}^{2}\right]$ & $\mathrm{A}_{\mathrm{s}}=3,68\left[\mathrm{~m}^{2}\right]$ \\
\hline $\begin{array}{c}\text { Masa jednej pełnej sekcji łuku długości } \\
\text { 2,49 [m], bez części ław fundamentowych } \\
\text { wylewanych na mokro }\end{array}$ & $\mathrm{G}_{\mathrm{s}}=25,9[\mathrm{ton}]$ & $\mathrm{G}_{\mathrm{s}}=21,5[\mathrm{ton}]$ \\
\hline Całkowita szerokość ławy fundamentowej & $2,34[\mathrm{~m}]$ & $2,3[\mathrm{~m}]$ \\
\hline $\begin{array}{c}\text { Kubatura części ławy fundamentowej } \\
\text { wykonanej na budowie dla całego obiektu }\end{array}$ & $84\left[\mathrm{~m}^{3}\right]$ & $37\left[\mathrm{~m}^{3}\right]$ \\
\hline Obciążenie zmienne, typ & $\mathrm{HA} \mathrm{i} \mathrm{HB45}$ & $\mathrm{HA} \mathrm{i} \mathrm{HB30}$ \\
\hline Wysokość nasypu & $11,75[\mathrm{~m}]$ & $4,96[\mathrm{~m}]$ \\
\hline Wysokość nasypu nad mostem & $9,7[\mathrm{~m}]$ & $3,36[\mathrm{~m}]$ \\
\hline
\end{tabular}

Po 5 latach od zakończenia budowy tych mostów sprawdzony został ich stan techniczny. Nie zauważono widocznych zarysowań na elementach konstrukcyjnych tych mostów i widocznego ich osiadania. Słuszna więc była wymiana gruntu dla tych konstrukcji.

\section{Konstrukcja łuku}

Prefabrykaty żelbetowe, z których wykonane są mosty pokazano na rysunku 1 i 2 . Beton użyty do ich wykonania jest klasy C40/50. Prefabrykaty wykonano w zakładzie prefabrykacji [10] i transportowano je drogą lądową na teren budowy. Do ich wbudowania użyto dźwigu samochodowego. W konstrukcji tych mostów występują dwie prefabrykowane żelbetowe części boczne łuku i ułożony na nich prefabrykowany żelbetowy strop. Po połączeniu tych elementów otrzymuje się most o kształcie łuku. Ponadto ze ścian bocznych łuku wyprowadzono na zewnątrz zbrojenie do części ławy fundamentowej wykonywanej 
na budowie. Zbrojenie to łączone było ze zbrojeniem podłużnym, ułożonym wzdłuż mostu. Po zamontowaniu zbrojenia i wykonaniu deskowania zabetonowano pozostałą część ławy. Następnie wykonano uszczelnienie połączeń miedzy prefabrykatami i po tym na ścianach wewnętrznych ułożono hydroizolację z dwóch warstw żywicy epoksydowej. Należy dodać, że projekt elementów żelbetowych tych mostów wykonała firma ABM z Irlandii [11]. Firma, w której pracował autor [9], była odpowiedzialna za cały projekt tych mostów wraz ze sprawdzeniem wykonanego projektu elementów żelbetowych przez firmę ABM.

\section{Zasypka za ścianami bocznymi mostu}

W mostach zintegrowanych rodzaj materiału stosowanego do ich zasypania oraz sposób jego ułożenia ma duży wpływ na rozkład sił wewnętrznych w ich elementach. Z tego względu na Wyspach Brytyjskich stosowane są zasypki z kruszywa łamanego klasy 6N i 6P. Szczegółowe informacje o nich podane są w specyfikacji do robót ziemnych [12] (tab. 2). Do budowy opisywanych mostów użyto zasypki o kącie tarcia wewnętrznego $\phi$ wahającym się w przedziale od $35^{\circ}$ do $38^{0}$.

Ważne jest, że przed rozpoczęciem budowy mostu, w miejscach przyszłych podpór wykonywane są odwierty geologiczne, wyznaczane są moduły sprężystości gruntu i obliczane jest osiadanie podpór.

Informacje te umożliwiają projektantowi zbudowanie modelu obliczeniowego konstrukcji, który dokładnie opisze faktyczne warunki jej posadowienia. Otrzymuje się w ten sposób model obliczeniowy konstrukcji na podporach sprężystych, poddających się wpływowi oddziałujących obciążeń stałych i zmiennych. Istotne jest również, że gdy sztywności elementów konstrukcyjnych są małe, konstrukcja jest podatna i lepiej współpracuje $\mathrm{z}$ otaczającym ją gruntem. Dzięki temu naprężenia w niej są mniejsze. $\mathrm{Z}$ tego względu w mostach zintegrowanych występują mniejsze przekroje elementów konstrukcyjnych i tym samym są one tańsze w budowie od innych mostów.

Tabela 2. Uziarnienie zasypek klasy 6N i 6P, na podstawie [12]

Table 2. Grading requirement for class $6 \mathrm{~N}$ and $6 \mathrm{P}$ material, based on [12]

\begin{tabular}{|c|c|c|}
\hline \multirow{2}{*}{$\begin{array}{c}\text { Sito kwadratowe } \\
{[\mathbf{m m}]}\end{array}$} & \multicolumn{2}{|c|}{ Przechodzi przez sito [\%] } \\
\cline { 2 - 3 } 6N & 6P \\
\hline 125 & & \\
\hline 100 & 100 \\
\hline 75 & \multicolumn{2}{|c|}{$65-100$} \\
\hline 37,5 & \multicolumn{2}{|c|}{$45-100$} \\
\hline 10 & \multicolumn{2}{|c|}{$15-75$} \\
\hline 5 & $10-60$ \\
\hline 0.6 & \multicolumn{2}{|c|}{$0-30$} \\
\hline 0.063 & $0-15$ \\
\hline
\end{tabular}




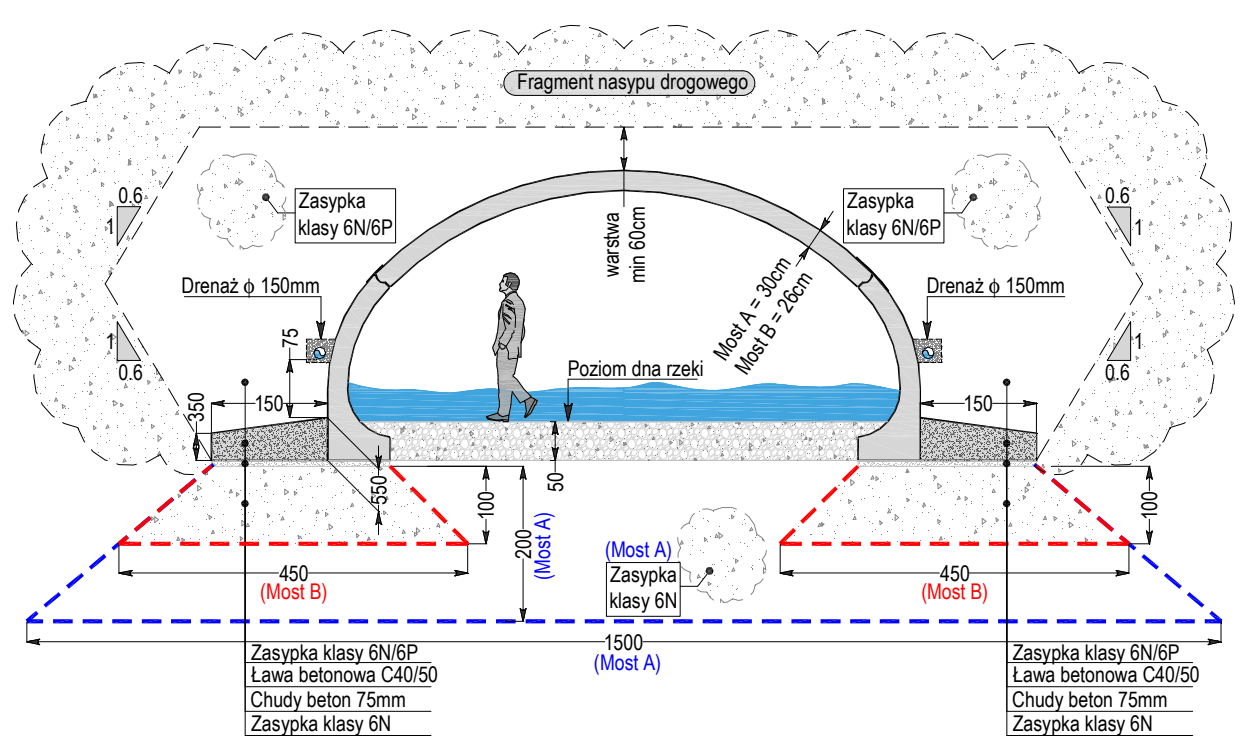

Rys. 3. Przekrój poprzeczny przez konstrukcje mostu i zasypki za jej ścianami

Fig. 3. The cross section of the bridge structure and backfill behind its walls

\section{Wnioski końcowe}

Obydwa mosty oddano do użytku w 2007 roku. Po pięciu latach wykonano przegląd opisanych mostów oraz innych, które zaprojektował autor na tym odcinku drogi. We wszystkich tych mostach nie pojawiły się zarysowania w ich konstrukcji i nierówne ich osiadania. Natomiast na jednym z mostów, na jego ścianach wewnętrznych widoczne były zacieki wody. Zacieki te pojawiły jedynie w kilku miejscach, tam gdzie znajdowały się połączenia miedzy prefabrykatami. Wobec tego powinno się mieć szczególną uwagę na wykonanie wszystkich połączeń miedzy prefabrykatami. Ponadto, w trakcie układania zasypki należy zwracać uwagę na te elementy, by ich nie uszkodzić.

Jednakże, warto wyraźnie stwierdzić, że przedstawione mosty zintegrowane bardzo dobrze współpracują z otaczającym je gruntem pod wpływem działania obciążeń stałych i zmiennych. Mosty te mogą być wykonane z elementów konstrukcyjnych o małym przekroju poprzecznym, w porównaniu do tradycyjnych rozwiązań konstrukcyjnych, w których nie uwzględniono współpracy gruntu z konstrukcją. Fakt ten czyni je tańszymi w budowie, w zestawieniu z tradycyjnie wykonywanymi mostami, ze względu na mniejsze zużycie materiału oraz brak deskowania i rusztowania przy ich wykonaniu. Autor sugeruje, że należy budować jak najwięcej mostów zintegrowanych w naszym kraju, ze względu na to, że jest to szybsze i tańsze rozwiązanie konstrukcyjne mostu. Należy mieć na uwadze, że w Polsce występują inne temperatury powietrza niż na Wyspach Brytyjskich z tego też względu, konieczne jest badanie tych konstrukcji w kra- 
jowych warunkach klimatycznych. Badania takie umożliwiłyby inżynierom mostowym wnikliwe poznanie pracy tych konstrukcji, co mogłoby prowadzić do stopniowego zwiększania ich długości. Na uwagę zasługuje fakt, że w Polsce pojawia się coraz więcej bardzo cennych publikacji na temat mostów zintegrowanych $[13,14,15,16]$. Świadczy to o rosnącym zainteresowaniu przez inżynierów mostowych w Polsce tymi konstrukcjami.

\section{Literatura}

[1] Helowicz A., Wiadukty zintegrowane jednoprzęsłowe z prefabrykowanych dźwigarów sprężonych. Konferencja Naukowa, Bydgoszcz-Krynica Zdrój, 20-25 Września 2015.

[2] Helowicz A., Mosty zintegrowane z prefabrykowanych dźwigarów sprężonych doświadczenie projektanta. Konferencja Naukowo-Techniczna Konstrukcje Sprężone, Kraków, 16-17 Kwietnia 2015.

[3] BA42/96: 2003. Volume 1, Section 3, Part 12. The Design of Integral Bridges. Design Manual for Roads and Bridges. The Stationery Office, London.

[4] BD37/01: 2001. Volume 1, Section 3, Part 14. Loads for Highway Bridges. Design Manual for Roads and Bridges. The Stationery Office, London. ISBN 0115523545.

[5] BD31/01: 2001. Volume 2, Section 2, Part 12. The design of buried concrete box and portal frame structures. Design Manual for Roads and Bridges. The Stationery Office, London.

[6] BS5400-04: 1990. British Standard. Steel, concrete and composite bridges - Part 4: Code of practice for design of concrete bridges. ISBN 0580184420.

[7] BS8006: 1995. British Standard. Code of practice for Strengthened/reinforced soils and other fills. ISBN 0580242161.

[8] National Road Authority. Urząd administracji rządowej w Irlandii, zarządzający drogami w tym kraju. www.nra.ie.

[9] Fehily and Timoney. Irlandzkie biuro konsultingowe. Cork Office, Core House, Pouladuff Road, Cork, Ireland. www.fehilytimoney.ie.

[10] Banagher Precast Concrete. Wykonawca prefabrykatów betonowych. www.bancrete.com.

[11] ABM Europe. Firma dostarczająca pełną dokumentację do systemu Matière CM4. www.abmeurope.com/

[12] Manual of Contract Documents for Road Works. Volume 1. Specification for Road Works. National Road Authority. March 2000.

[13] Furtak K., Wrana B., Mosty zintegrowane. Wydawnictwo Komunikacji i Łączności Warszawa. 2005. ISBN: 832061550X.

[14] Machelski Cz., Modelowanie mostowych konstrukcji gruntowo-powłokowych, Dolnośląskie Wydawnictwo Edukacyjne, 2008, ISBN: 978-83-7125-163-4.

[15] Machelski Cz., Budowa konstrukcji gruntowo-powłokowych. Dolnośląskie Wydawnictwo Edukacyjne. 2013. ISBN: 978-83-7125-234-1.

[16] Jarosz J., Radomski W., Analiza numeryczna przemieszczeń mostowych konstrukcji zintegrowanych. Inżynieria i Budownictwo, nr 6/2013. 


\section{INTEGRAL ARCH BRIDGES MATIÈRE CM4 SYSTEM - THE DESIGNER EXPERIENCE}

\section{Summary}

The paper presents examples of single span integral Matière CM4 $40 \mathrm{~m} 2$ arch bridges, built using precast concrete elements. Presented bridges have been designed by the author of this paper. All the structures have been constructed along N11 Gorey to Arklow link road over river Banoge in Ireland. Some advantages and disadvantages of those structures have been discussed. The author is focused in particular on an integral bridge design, its construction process, construction cost, and behavior during its service. The article concludes with a summary of author skills and knowledge about the design of integral Matière CM4 arch bridges, with recommendations as to the design of those bridges in Poland.

Keywords: integral bridge, precast Matière arch bridge, single span bridge, design and construction

Przestano do redakcji: 07.06.2016 $r$.

Przyjęto do druku: 30.06.2016 r.

DOI: $10.7862 /$ rb.2016.102 